\title{
Comments on "Determination of Mercury, Cadmium, Lead, Zinc, Selenium and Iron by ICP-OES in Mushroom Samples from Around Thermal Power Plant in Muğla, Turkey". doi:10.1007/s00128-011-0357-1
}

\author{
Jerzy Falandysz
}

Received: 21 January 2012/Accepted: 7 February 2012/Published online: 28 February 2012

(c) The Author(s) 2012. This article is published with open access at Springerlink.com

\begin{abstract}
In several articles on trace elements in mushrooms erroneous data were published on minerals sequestered in fruiting bodies. The biased analytical data published gave a false picture on the composition and nutritional value of mushrooms with respect to minerals. Wild mushrooms are relatively rich in trace elements and some species can hyperaccumulate certain metals. Selenium as reported in the referenced article is discussed in light of typical Se concentrations determined using validated methods as reported by other authors.
\end{abstract}

Keywords Fungi - Mushrooms · ICP-OES - Selenium · Trace metals . Wild foods

I read the article on contents of mercury, cadmium, lead, zinc, selenium and iron in mushrooms from an area affected by a thermal power plant fueled with hard coal. I came to this report with a particular interest with respect to Se concentrations. Selenium is vital to human health and a good bio-available source of this element from foods is needed to maintain good health (Jarzyńska and Falandysz 2011a). Selenium is found in different chemical species, has a relatively narrow margin of safety between an adequate, inadequate and excess intake, is highly potent and has great health impact. Hence, accurate data on Se content of foods are essential both in research and applicable surveys to enable health risk assessments to be carried out.

\footnotetext{
J. Falandysz ( $\square)$

Research Group of Environmental Chemistry, Ecotoxicology and Food Toxicology, Institute of Environmental Sciences and Public Health, University of Gdańsk, 18 Sobieskiego Str., 80-952 Gdańsk, Poland

e-mail: jfalandy@chem.univ.gda.pl
}

Both cultivated and wild mushrooms can be important constituents of the market basket, especially to vegans and vegetarians who may otherwise lack certain nutrients from their diet. Consumption rates of mushrooms vary largely between the nations, ethnic groups and regions of the world (Zhang et al. 2010). Many mushrooms are rich in $\mathrm{K}, \mathrm{P}, \mathrm{Rb}$, $\mathrm{Cu}, \mathrm{Mn}$ and $\mathrm{Zn}$ and in addition some species are abundant in a specific element or elements e.g. $\mathrm{Ag}, \mathrm{Cd}, \mathrm{Cu}, \mathrm{Fe}, \mathrm{Hg}$, Se, V (Borovička and Řanda 2007; Borovička et al. 2010; Costa-Silva et al. 2011; Falandysz et al. 2001, 2002, 2003, 2004, 2007a, b, c, d, 2008a, b, 2012; Gucia et al. 2012; Jarzyńska et al. 2011). All mushrooms contain Se in flesh but a few edible wild mushrooms are specifically rich in Se ( $>10 \mu \mathrm{g} / \mathrm{g}$ dry weight), while in many the content is $<1.0 \mu \mathrm{g} / \mathrm{g}$ dw (Fig. 1; Falandysz 2008).

The cultivated mushrooms (Agaricus bisporus), Oyster Mushrooms (Pleurotus ostreatus) and Shitake (Lentinus edeodes) are usually relatively poor in Se (Falandysz 2008). In the USA, the cultivated species: A. bisporus (the White Button Mushroom, Portabella and Baby Bella varieties), L. edeodes, P. ostreatus, P. erungii (King Trumpet), Hipsizygus tessulatus (Brown Beech or Brown Clamshell Mushroom), Flammulina veluipes (Enoki) and Grifola fromulosa (Maitake) contained Se in concentrations varying between 0.01 and $2.7 \mu \mathrm{g} / \mathrm{g} \mathrm{dw}$, and in a consignment of A. bisporus concentrations were $2.7 \mu \mathrm{g} / \mathrm{g} \mathrm{dw}$ and in P. ostreatus $0.2 \mu \mathrm{g} / \mathrm{g} \mathrm{dw}$ (Hong et al. 2011).

Some common cultivated mushrooms if developed in substratum fortified with added Se or substratum made of biomass collected from a selenoferous area or if prepared from Se-laden plants, can be enriched in Se (Bhatia et al. 2011; Falandysz 2008; Hong et al. 2011; Rodriquez-Estrada et al. 2009).

Kula et al. (2011) reported high concentrations of Se between 18.7 and $67.10 \mu \mathrm{g} / \mathrm{g} \mathrm{dw}$ for all fifteen species of mushrooms examined. For some of these mushrooms, i.e. 


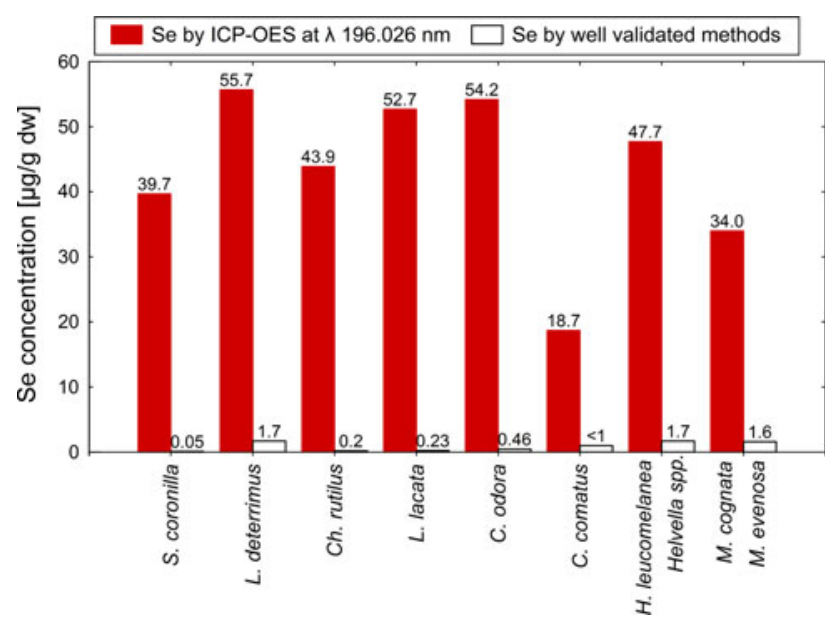

Fig. 1 The values of Se concentrations reported in certain mushrooms as determined using ICP-OES by Kula et al. (2011) (left bar) and by other researchers when using generally accepted methods (right bar; as cited after Falandysz (2008) and Mandić et al. (1991); the mushroom names are such as Stropharia coronilla (S. coronilla); Lactarius deterrimus (L. deterrimus); Chroogompus rutilus (Ch. rutilus); Laccaria lacata (L. laccata); Clitocybe odora var. alba (C. odora); Coprinus comatus (C. comatus); Helvella leucomelanea (H. leucomelanea) (filled bar) and various Helvella spp. (empty bar); Melanoleuca cognata (M. cognata) (filled bar) and M. evenosa (empty bar) (color figure available online)

Stropharia coronilla, Lactarius deterrimus, Chroogompus rutilus, Laccaria lacata, Clitocybe odora var. alba, Coprinus comatus, Helvella leucomelanea, Melanoleuca cognate, data on Se have been reported by other authors - see review by Falandysz (2008).

Kula et al. (2011) determined Se by inductively coupled plasma - optical emissions spectroscopy (ICP-OES; ICPAES). Their data for eight mushrooms and "reference data" for the same species determined by other authors are given in Fig. 1. These "reference values" (Fig. 1) are valid and were obtained by widely accepted analytical methods such as hydride generation - atomic absorption spectroscopy (HG AAS), instrumental neutron activation analysis (INAA) and others. The discrepancies between erroneous Se data by ICP-OES and valid by other methods are evident (Fig. 1).

Good data on Se determined by graphite furnace AAS in mushrooms such as Panellus stipticus, Tricholoma terreum, T. virgatum, Entoloma sinuatum, Boletus edulis, B. luridus, Suillus granulatus, Amanita muscaria, A. pantherina, Agaricus arvensis, A. porphyrizon, A. silvicola, Leucoagaricus leucothites, L. nympharum, Macrolepiota procera and Russula foetens from Turkey have been reported by Tuzen et al. (2007). They imply on typical concentrations of Se in soils in Turkey and fit well with Se data for the same mushrooms but collected elsewhere in the world - as examined by several researchers, and reviewed by Falandysz (2008).
The matrix effects from biological samples due to presence of carbon but also sulfur, phosphorus and bromine can cause non-spectral interferences and it can lead to high Se concentrations as determined by ICP-AES - as discussed by several authors earlier (Grindla et al. 2007; Machat et al. 2002). Determination of Se as well as of $\mathrm{Hg}$ by ICP-AES even after efficient digestion/oxidation of biological material (mushrooms and plant) in closed PTFE vessels using concentrated nitric acid and with aid of microwave energy can lead to imprecise and frequently inaccurate results, when compared, respectively to HG-AAS and cold vapour - atomic absorption spectroscopy (CV-AAS) (Jarzyńska et al. 2012; Jarzyńska and Falandysz 2011b).

In the analytical quality control guidelines for the publication of analytical results of chemical analysis in foodstuffs by Jorhem et al. (2011) is stated that "suspicious of poor analytical quality of published elemental results have been mounting over the years". To help the researchers, authors and reviewers, the check-list for the description of quality control criteria was created by these authors and the QC-guidelines are given for an open distribution (Jorhem et al. 2011). In the "Analytical parameter" part of these QC-guidelines in the sampling, methodology and certified reference materials sections, the primarily points are: (i) sampling representativity, appropriate choice of method and relevance of the certified material matrix, respectively (Jorhem et al. 2011).

In reports on minerals in mushrooms information on the number of samples (single or pooled, and number of fruiting bodies - mushrooms, if pooled sample were examined) collected and examined is often lacking detail or no such information at all is provided. It is left for the reader to guess that only a single specimen (fruiting body) was collected and examined and a value of standard deviation given refers to a single result and reflects only a variability of instrumental measurements of the same sample. Representative sample collection is important and should be made a priority, and to evaluate natural variability, the sample (specimen) number has to be no fewer than 15 in order to be satisfactory (Eckschlager 1974).

Borovička and ̌̌anda (2007) discussed recently erroneously reported concentrations of iron $(\mathrm{Fe})$ in mushrooms by some authors and the remarks there seem to apply also to data reported by Kula et al. (2011).

Acknowledgments This study has been supported by the Ministry of Science and Higher Education under grant no. DS-8130-4-0092-1.

Open Access This article is distributed under the terms of the Creative Commons Attribution License which permits any use, distribution, and reproduction in any medium, provided the original author(s) and the source are credited. 


\section{References}

Bhatia P, Prakash R, Cameotra SS, Aureli F, Cubadda F, D'Amato M, Nagaraja TP (2011) Fortification of edible mushrooms with selenium using naturally enriched substrates. In: 4th international IUPAC symposium for trace elements in foods (TEF-4). King's College, Aberdeen, Scotland, 19-22 June 2011. P/19/ 0040

Borovička J, Řanda Z (2007) Distribution of iron, cobalt, zinc and selenium in macrofungi. Mycology Prog 6:249-259

Borovička J, Kotrba P, Gryndler M, Mihaljevič M, Řanda Z, Rohovec J, Cajthaml T, Stijve T, Dunn CE (2010) Bioaccumulation of silver in ectomycorrhizal and saprobic macrofungi from pristine and polluted areas. Sci Total Environ 408:2733-2744

Costa-Silva F, Marques G, Matos CC, Barros AIRNA, Nunes FM (2011) Selenium contents of Portuguese commercial and wild edible mushrooms. Food Chem 126:91-96

Eckschlager K (1974) Chyby chemických rozborů (Polish edition) Państwowe Wydawnictwo Naukowe, Warszawa

Falandysz J (2008) Selenium in edible mushrooms. J Environ Sci Health C 26:256-299

Falandysz J, Szymczyk K, Ichihashi H, Bielawski L, Gucia M, Frankowska A, Yamasaki S (2001) ICP/MS and ICP/AES elemental analysis (38 elements) of edible wild mushrooms growing in Poland. Food Addit Contam 18:503-513

Falandysz J, Bielawski L, Kannan K, Gucia M, Lipka K, Brzostowski A (2002) Mercury in wild mushrooms and underlying soil substrate from the great lakes land in Poland. J Environ Monit 4:473-476

Falandysz J, Gucia M, Brzostowski A, Kawano M, Bielawski L, Frankowska A, Wyrzykowska B (2003) Content and bioconcentration of mercury in mushrooms from northern Poland. Food Addit Contam 20:247-253

Falandysz J, Jędrusiak A, Lipka K, Kannan K, Kawano M, Gucia M, Brzostowski A, Dadej M (2004) Mercury in wild mushrooms and underlying soil substrate from Koszalin, North-central Poland. Chemosphere 54:461-466

Falandysz J, Gucia M, Mazur A (2007a) Content and bioconcentration factors of mercury by Parasol Mushroom Macrolepiota procera. J Environ Sci Health B 42:735-740

Falandysz J, Kunito T, Kubota R, Bielawski L, Mazur A, Falandysz JJ, Tanabe S (2007b) Selected elements in Brown Birch Scaber Stalk Leccinum scabrum. J Environ Sci Health A 42:2081-2088

Falandysz J, Kunito T, Kubota R, Lipka K, Mazur A, Falandysz JJ, Tanabe S (2007c) Selected elements in Fly Agaric Amanita muscaria. J Environ Sci Health A 42:1615-1623

Falandysz J, Kunito T, Kubota R, Brzostowski A, Mazur A, Falandysz JJ, Tanabe S (2007d) Selected elements of Poison Pax Paxillus involutus. J Environ Sci Health A 42:1161-1168

Falandysz J, Kunito T, Kubota R, Bielawski L, Frankowska A, Falandysz JJ, Tanabe S (2008a) Multivariate characterization of elements accumulated in King Bolete Boletus edulis mushroom at lowland and high mountain regions. J Environ Sci Health A 43:1692-1699

Falandysz J, Kunito T, Kubota R, Gucia M, Mazur A, Falandysz JJ, Tanabe S (2008b) Some mineral constituents of Parasol Mushroom Macrolepiota procera. J Environ Sci Health B 43:187-192

Falandysz J, Widzicka E, Kojta AK, Jarzyńska G, Drewnowska M, Danisiewicz-Czupryńska D, Dryżałowska A, Lenz E, Nnorom IC (2012) Mercury in Common Chanterelles mushrooms:
Cantharellus spp. update. Food Chem. doi:10.1016/j.foodchem. 2012.01.102

Grindla G, Mora J, Gras L, de Loos-Vollebregt MTC (2007) Carbon related matrix effects in ICP-AES. XIV EuroAnalysis, Antwerp, Belgium, 9-14 September 2007. http://hdl.handle.net/10045/ 13406

Gucia M, Kojta AK, Jarzyńska G, Rafał E, Roszak M, Osiej I, Falandysz J (2012) Multivariate analysis of mineral constituents of edible Parasol Mushroom (Macrolepiota procera) and soils beneath fruiting bodies collected from Northern Poland. Environ Sci Pollut Res 19:416-431

Hong J, Bañuelos GS, Fowler T, Lin Z-Q (2011) Use of seleniumladen plant materials from phytoremediation to produce selenium-biofortified edible mushrooms. In: ICOBTE 2011, 11th international conference on the biogeochemistry of trace elements. Conference proceedings Parte I, Congress Center, Florence, Italy, July 3-7, 2011, pp 349-350

Jarzyńska G, Falandysz J (2011a) Selenium and 17 other largely essential and toxic metals in muscle and organ meats of Red Deer (Cervus elaphus) - Consequences to human health. Environm Intern 37:882-888

Jarzyńska G, Falandysz J (2011b) The determination of mercury in mushrooms by CV-AAS and ICP-AES techniques. J Environ Sci Health A 46:569-573

Jarzyńska G, Gucia M, Kojta AK, Rezulak K, Falandysz J (2011) Profile of trace elements in Parasol Mushroom (Macrolepiota procera) from Tucholskie Forests. J Environ Sci Health B 46: $741-751$

Jarzyńska G, Kojta AK, Drewnowska M, Falandysz J (2012) Notes on selenium data in mushrooms determined by ICP-AES and HGASA techniques. African J Agric Res 7 (in press)

Jorhem L, Engman J, Sundström B (2011) Analytical quality control-guidelines for the publication of analytical results of chemical analysis in foodstuffs. TEF-4 Protocol No 5 QCguideline 2011-10-11.pdf (Obiekt application/pdf)

Kula İ, Solak MH, Uğurlu M, Işiloğlu M, Arslan Y (2011) Determination of mercury, cadmium, lead, zinc, selenium and iron by ICP-OES in mushroom samples from around thermal power plant in Muğla, Turkey. Bull Environm Contam Toxicol 87:276-280. doi:10.1007/s00128-011-0357-1

Machat J, Otruba V, Kanicky V (2002) Spectral and non-spectral interferences in the determination of selenium by inductively coupled plasma atomic emission spectrometry. J Anal At Spectrom 17:1096-1102

Mandić M, Grgić J, Grgić Z, Trstenjak-Petrović Ž (1991) The natural level of selenium in wildlife mushrooms in Eastern Croatia. Prehrambeno Technol Biotechnol 29:159-161

Rodriquez-Estrada AE, Lee H-J, Beelman RB, Jimenez-Gasco M, Royse DJ (2009) Enhancemant of the antioxidants ergothineine and selenium in Pleurotus eryngi var. eryngi basidiomata through cultural practice. World J Microbiol Biotechnol 25: $1597-1607$

Tuzen M, Sesli E, Soylak M (2007) Trace element levels of mushroom species from East Black Sea region of Turkey. Food Control 18:806-810

Zhang D, Frankowska A, Jarzyńska G, Kojta AK, Drewnowska M, Wydmańska D, Bielawski L, Wang J, Falandysz J (2010) Metals of King Bolete (Boletus edulis) collected at the same site over two years. African J Agric Res 5:3050-3055 